\title{
Consequence assessment of explosions for fuel-air mixtures at hazardous production facilities
}

\author{
Anton Byzov ${ }^{1, *}$, Anastasiya Telegina ${ }^{1}$, Ivan Korotkiy ${ }^{1}$, and Jaromír Veber ${ }^{2}$ \\ ${ }^{1}$ Peter the Great St. Petersburg, Polytechnic University, 29 Polytechnicheskaya St., St. Petersburg, 195251 \\ ${ }^{2}$ Czech Technical University in Prague, Jugoslávských partyzánů 1580/3, 16000 Prague 6 - Dejvice, Czech Republic
}

\begin{abstract}
The article reviewed one of the known accidents with explosions of fuel assemblies both in domestic and foreign enterprises, and analyzed the causes of its occurrence. With the help of several computational methods, the sizes of the zones of air-shock wave (ASW) were determined and compared with the "real" data, and situational plans with zones of destruction were constructed.
\end{abstract}

\section{Introduction}

Modern technologies are impossible without the use of explosive substances. Fuel-air mixtures (FA), fuel and lubricants (fuels and lubricants), flammable liquids (flammable liquids) are used in all areas of society, both in industry and in everyday life [1, 2]. One of the main tasks of society is to ensure the safety of the population and territories from emergency situations (ES) of natural and man-made characters [3]. Among man-made disasters, the most dangerous are explosions and fires during storage and transportation of oil and petroleum products, as well as other types of fuel [4-5].

The relevance of studies of explosions of fuel-air mixtures is due to the significant risk of accidents associated with them and the need to predict the extent of possible dangerous consequences when designing hazardous production facilities and developing additional safety measures $[1,6,7,8]$. When considering the processes of explosive transformations of fuel assemblies, special attention is paid to possible modes of combustion of an explosive cloud and consideration of factors determining the conditions for the onset of detonation or deflagration with a corresponding speed of flame front propagation [9]. Variants of accidents can lead to catastrophic consequences and a significant loss of human life, as well as cause irreparable damage to the environment [10, 11].

After analyzing the existing practical methods for assessing the consequences of an explosion [12, 13], it is proposed to use a method that allows to take into account the energy characteristics of gas-vapor mixtures, associating the consequences of a gas-vapor cloud explosion with a specific potentially dangerous substance.

The aim of this study is to analyze the approaches and calculation methods for assessing the consequences of accidents associated with fuel-air mixtures explosions and the development of possible solutions arising from the spill of gasoline.

\section{Materials and methods}

In the process of writing the article, the following chain of research methods, both empirical and theoretical, was compiled, which will allow to achieve the purpose:

1. Statement of the problem on the study consequence assessment of explosions for fuel-air mixtures at hazardous production facilities [3]. This issue has been under consideration for several years, thanks to which one can take into account the mistakes of previous researchers and improve their possible solutions to this problem.

2. The study of literature, documents allows you to study the work of other researchers for a better understanding of the topic [14-25], helps to find the necessary relevant information, through which the direction of research is formed.

3 . Analysis of the information received contributes to its systematization [15] and helps decompose it into features and properties in order to study the problem more specifically.

4. A mental experiment allows you to recreate the picture of what is happening without the use of real objects, which will help avoid unforeseen emergencies [16-17].

5. The measurements are used to determine a more accurate result that can be compared with other results from reliable sources [15-17], which will help identify and resolve inconsistencies

6. Conducting the analogy and comparison with the previously published studies [2] will allow to take into account the deficiencies and to identify the most appropriate ways to solve the problem.

7. Identification and resolution of contradictions will allow improving calculation methods and measures to prevent the development of accidents at hazardous

\footnotetext{
* Corresponding author: antonbyzov@gmail.com
} 
production facilities in previous theories or in practical research activities. [18-19].

\section{Results}

For the subsequent analysis, the accident that took place on July 28, 1948 at the BASF facility in Ludwigshafen (Germany) was considered. According to available data [20], a dimethyl ether tank was located on Anilinfabriksstrassa. According to the official version, the tank was overfilled, and when it was heated by solar energy, a hydraulic fracture occurred, resulting in a complete loss of its content - 30.4 tons of dimethyl ether.

As a result of the explosion of a vapor cloud in accordance with the sources [20], the area of the zone of serious destruction was 300 thousand $\mathrm{m} 2$. It was also established that 207 people died and 3808 were injured, 500 of them were serious. Victims outside the enterprise are absent.

According to the damage scheme, the radius of the zone of total damage was about $160 \mathrm{~m}$. The accident report presented a description of the sequence of events based on testimony, which indicated a whistling sound characteristic of steam produced by the locomotive and the appearance of a brown-white cloud before the main explosion. The scheme of destruction is shown in Figure 1.

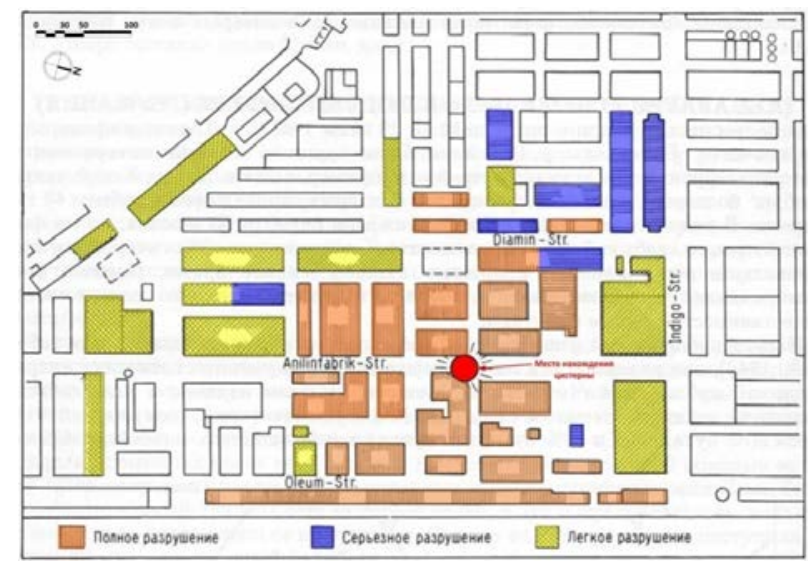

Fig. 1. The scheme of destruction in Ludwigshafen July 28, 1948.

An approximate scheme for the development of an accident is as follows: destruction of a dimethyl ether tank $\rightarrow$ release of hazardous substance into the surrounding space $\rightarrow$ intensive mixing with air, formation of an explosive vapor-gas cloud $\rightarrow$ ignition of a cloud when an ignition source appears, explosion of a fuel assembly cloud $\rightarrow$ impact of a shock wave on people and nearby objects [14].

To evaluate the consequences and comparative analysis with real data on the consequences of the accident in Ludwigshafen, a number of computational methods were chosen that allow a quantitative assessment of the parameters of the air shock wave (ASW) arising from the combustion of the FA cloud. The situational plan with the applied zones of complete destruction, determined by various methods, is presented in Figure 2.

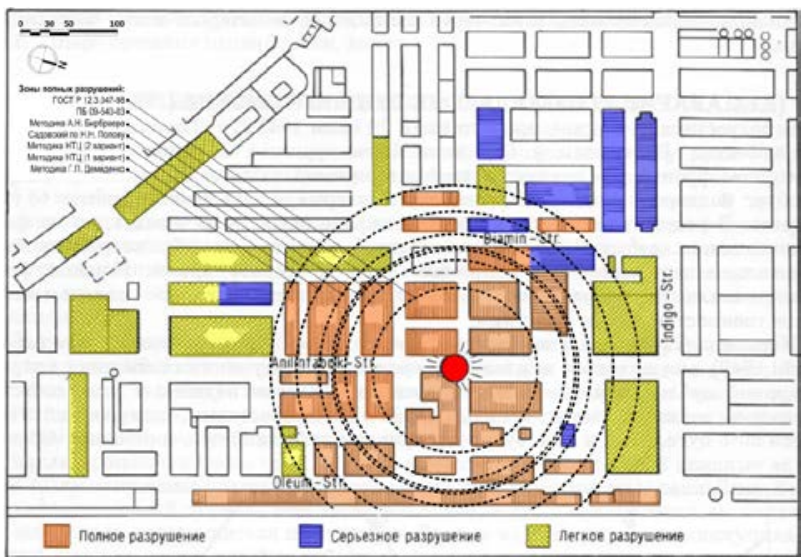

Fig. 2. Situation plan with areas of complete destruction.

The situational plan with the applied zones of average destruction determined by various methods is presented in Figure 3.

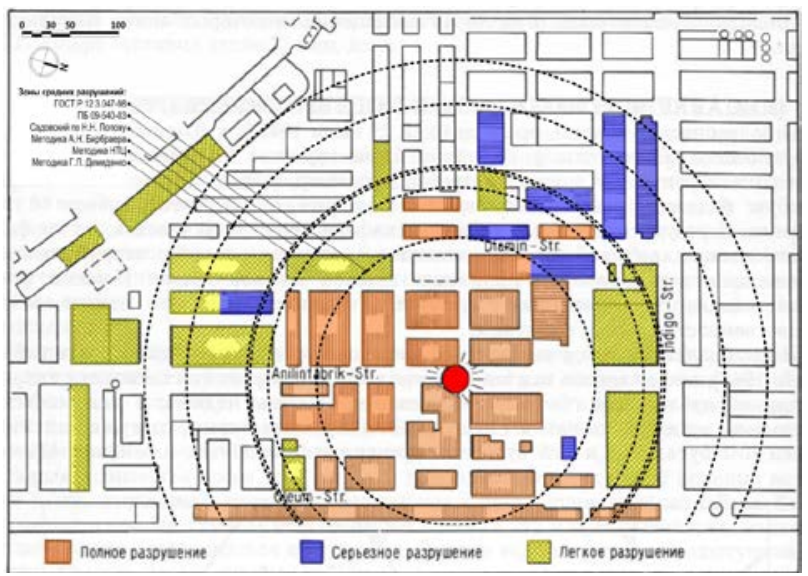

Fig. 3. Situation plan with areas of average destruction.

As a result of the calculations carried out using several methods for estimating [21-26] the effects of fuel assembly explosions, the sizes of zones of impact of explosives were obtained. The dimensions of the zones of destruction in accordance with the accepted universal criteria are given in Table 1.

The analysis revealed the presence of discrepancies in the results, which is explained by the different need to specify the source data and the certainty of the explosion conditions, the difference between the used mathematical dependencies.

\section{Conclusions}

Summing up, it was found that the results of calculations obtained by the method described in GD 03-409-01 "Methodology for assessing the consequences of emergency explosions of fuel-air mixtures" [26], for complete destruction, have a deviation from the "real" value of no more than $3 \%$, average damage not more than $10 \%$. The obtained results confirm the sequence of application of the methodology when conducting 
Table 1. The main results of the calculation of destruction zones.

\begin{tabular}{|l|c|c|c|c|}
\hline \multicolumn{1}{|c|}{ Technique } & \multicolumn{3}{c|}{ The radii of the destruction zone, m } \\
\cline { 2 - 5 } & total & severe & middle & weak \\
\hline Sadovsky by N.N. Popov [19] & 128.2 & 153.3 & 214.3 & 338.0 \\
\hline Methodology G.P. Demidenko [20] & 191.6 & 230.9 & 324.1 & 504.1 \\
\hline Methodology A.N. Birbraera [21] & 125.0 & 152.4 & 217.4 & 345.5 \\
\hline State standard 12.3.047-2012 [22] & 85.5 & 102.8 & 145.1 & 230.8 \\
\hline $\begin{array}{l}\text { Federal rules and regulations in the field of } \\
\text { industrial safety [25] }\end{array}$ & 114.1 & 153.0 & 195.5 & 570.4 \\
\hline Safety guide (1 option) [24] & 164.7 & 196.0 & 280.0 & 426.0 \\
\hline Safety guide (2 option) [24] & 141.0 & 197.5 & 280.0 & 426.0 \\
\hline
\end{tabular}

calculations to determine the damaging parameters of explosions of fuel-air mixtures. This result is quite convincing and confirms the admissibility of the wide application of this technique.

The particular danger of accidents involving explosions of air-fuel mixtures is due to the possibility of its cascade development [27-29], i.e. involvement in the accident of the neighboring equipment containing hazardous substances, and its destruction, as well as the drift of FA clouds over considerable distances with a late initiation of the ignition source. Therefore, this problem is relevant today and requires special attention to the consideration of such accidents to prevent possible areas of catastrophic destruction and minimizing human losses.

\section{References}

1. A.Z. Mendiburu, J.A. de Carvalho Jr, C.R. Coronado, Method for determination of flammability limits of gaseous compounds diluted with N2 and CO2 in air Fuel, 226, 65-80 (2018)

2. J. Casal, Evaluation of the Effects and Consequences of Major Accidents in Industrial Plants: Second Edition, 1-553 (2017)

3. I.V. Yegorova, H.H. Petrenko, N.B. Rudepko, H.H. Gracheva, Consequences assessment of emergency explosions of fuel-air mixtures at enterprises of the full power complex, 3 (35) (2016)

4. K. Kempna, J. Smolka, M. Kvarcak, I. Kricfalusi, Z. Stejskal, T. Hozjan, D. Kolaitis, Fire Safety Protection Assessment of Industrial Technologies, J. of Physics: Conference Series, 1107 (4), 042036 (2018)

5. A. Nikulin, A.Y. Nikulina, Assessment of occupational health and safety effectiveness at a mining company. Ecology, Environment and Conservation, 23 (1), 351-355 (2017)

6. L.I. Ushvitskii, T.A. Kulagovskaya, A.A. TerGrigor'yants, I.V. Solovyova, E.S. Mezentseva, Methodological tools for risk assessment in industrial enterprises, International J. of Economics and Financial Issues, 5 (4), 1011-1016 (2015)

7. F. Bryukhan, I. Lavrusevich, A. Vinogradov, I. Vinogradov, Consideration of external natural impacts in the design of hazardous production facilities M.: Web of Conferences, 251, 06001 (2018)

8. Y. Redutskiy, Optimization of Safety Instrumented System Design and Maintenance Frequency for Oil and Gas Industry Processes, Management and Production Engineering Review, 8 (1), 46-59 (2017)

9. N. Khakzad, Which Fire to Extinguish First? A Risk-Informed Approach to Emergency Response in Oil Terminals Risk Analysis, 38 (7), 1444-1454 (2018)

10. Y. Tang, J. Jing, Z. Zhang, Y. Yang, A quantitative risk analysis method for the high hazard mechanical system in petroleum and petrochemical industry, Energies, 11 (1) (2018)

11. Z. Tzenova, Calculation of individual risk and social risk in accident situations in industrial production, AIP Conference Proceedings, 2048 (2018)

12. A.V. Matveev, A.V. Maksimov, O.V. Shcherbakov, A.S.Smirnov, Method of estimation for the reliability of quantitative risk analysis on objects of oil and gas industry. Pozharovzryvo-bezopasnost / Fire and Explosion Safety, 27 (1), 35-49 (2018)

13. A. Maria Gligor, V. Petrescu, Considerations on determining the explosion risk and the areas with explosion hazard in a natural gas compressor station, M.: Web of Conferences, 184, 03005 (2018)

14. S.G. Alexeev, L.V. Poluyan, E.S. Gur'ev, N.M. Barbin, Methods of Predicting Vapor Cloud Exp1losions in Enclosed Spaces, Coke and Chemistry, 61 (8), 312-317 (2018)

15. S.V. Burtsev, O.Ph. Basyrov, Integrated approach in the field of industrial safety and labour protection Ugol', (4), 26-30 (2018)

16. R.D. Jovanovic, K. Strug, B. Swiatkowski, S. Kakietek, K. Jagiello, D.B. Cvetinovic, Experimental and numerical investigation of flame characteristics during swirl burner operation under conventional and oxy-fuel conditions, Thermal Science, 21 (3), 1463-1477 (2017)

17. C. Zhang, Analysis of Fire Safety System for Storage Enterprises of Dangerous Chemicals, Procedia Engineering, 211, 986-995 (2018)

18. I.V. Orishchenko, N.V. Petrenko, V.N. Litvinov, N.N. Gracheva, N.B. Rudenko, Information systems and processes in the tasks implementation 
of assessing the consequences of the fuel mixture emergency explosions, 193-204 (2016)

19. N. Arefiev, M. Mikhalev, D. Zotov, K. Zotov, N. Vatin, O. Nikonova, O. Skvortsova, S. Pavlov, T. Chashina, T. Kuchurina, V. Terleev, V. Badenko, Y. Volkova, V. Salikov, K. Strelets, M. Petrochenko, A. Rechinsky, Physical modeling of suspended sediment deposition in marine intakes of nuclear power plants, Procedia Engineering, 117 (1), 32-38 (2015)

20. V. Marshall, Major chemicals hazards: translated from English. M.: World, 672 (1989)

21. A. M. Kozlitin, Development of the theory and methods of risk assessment for ensuring industrial safety of oil and gas facilities [Electronic resource]: Dis. Dr. techn. Sciences: 05.26.03. Saratov: RSL (From the funds of the Russian State Library) (2006)

22. G.P. Demidenko, Protection of objects of national economy from weapons of mass destruction, 287 (Orlov, Kiev) (1989)

23. A.N. Birbraer, Extreme effects on facilities, 594 (SPb.: Ed. Polytechnic University, 2009)

24. State standard 12.3.047-2012. Fire safety of technological processes. General requirements. Control methods.

25. Federal norms and rules in the field of industrial safety "General rules of explosion safety for explosive chemical, petrochemical and oil refining industries"

26. Safety guide "Methodology for assessing the consequences of accidental explosions for fuel-air mixtures"

27. M.Yu. Zemenkova, Y.D. Zemenkov, A.L. Pimnev, E.V. Kurushina, System of Controlling the Reliability of Hydraulic Machinery in Oil and Gas Facilities, IOP Conference Series: Materials Science and Engineering, 127 (1) (2016)

28. G. Stankovic, S. Petelin, P. Vidmar, M. Perkovic, Influence of implementation of technologically advanced evacuation models on the process of decreasing the risk during accidents in an LNG terminal, Transport Problems, 12 (1), 25-38 (2017)

29. B. Zhang, Y. Liu, S. Qiao, A Quantitative Individual Risk Assessment Method in Process Facilities with Toxic Gas Release Hazards: A Combined Scenario Set and CFD Approach, Process Safety Progress, 38 (1), 52-60 (2019) 